\title{
Hybrid Neural - Based Model for Predicting the Construction Project Performance of High - Rise Building Projects in Metro Manila, Philippines
}

\author{
Jucar FERNANDEZ ${ }^{\mathrm{a}}$, Dante L. SILVA ${ }^{\mathrm{a}, \mathrm{b} 1}$, Kevin Lawrence M. De JESUS ${ }^{\mathrm{a}}$ \\ ${ }^{a}$ School of Graduate Studies, Mapua University, Manila, Philippines \\ ${ }^{b}$ School of Civil, Environmental and Geological Engineering, Mapua University, \\ Manila, Philippines
}

\begin{abstract}
Assessing construction project performance through adapting an innovative approach can multiply the production of high-quality project outputs which is a catalyst to the socio-economic progress of a country. Preliminary data collection was employed through a meta-cognitive analysis of reviewing related literature which directs to the backbone of qualitative information that is relevant to the periodically experienced construction performance-influencing factors and to develop an assessment questionnaire about the influencing factors affecting the project performance. The IBM SPSS program was used to verify the reliability and consistency of the fundamental statistics of the questionnaire responses of cost, time and quality performance ratings. A predictive mathematical model was developed for forecasting cost, time, and quality performance rating employing LevenbergMarquardt training algorithm with Hyperbolic Tangent Sigmoid function. The prediction model result shows a highly satisfying performance on its variance from the substantive values and suggests a high correlation between these values. The relative importance of the factors affecting the cost, time, and quality performance rating was calculated via sensitivity analysis through connection weights using Garson's Algorithm to view the order of influence of the parameters that have great significance to the success of a project.
\end{abstract}

Keywords: Construction analytics, project performance, neural network, sensitivity analysis, KPI dashboard

\section{Introduction}

Construction is considered a major industry throughout the world which calculating a colossal proportion of most countries' gross domestic product and gross national product. The key importance of the construction sector is not only with its whopping size but also its eminent role as a catalyst in economic growth. Assessing construction project performance using a cutting-edge approach can multiply the production of high-quality project outputs which is a critical contributor to the social and economic development of a country [1].

${ }^{1}$ Corresponding author: Dante L. SILVA, School of Graduate Studies, Mapua University, Manila, Philippines; E-mail: dantesilva2000@yahoo.com. 
The construction industry is very complex because it involves different parties of internal and external stakeholders: owners, consultants, general contractors, and subcontractors [2]. Moreover, several Key Performance Indicators (KPI) had been employed and used to assess and evaluate project performance. However, the time, cost, and quality indicators are the most prevalent performance evaluation factors which widely used on construction analytics and reporting dashboards [3]. Acknowledging the impact of a construction project in this time of pandemic for stakeholder key goals for the overall growth of the project suggests that there is a compelling need to ensure the quality of management tools and approach throughout the execution process. Therefore, it is vital nowadays to develop a new technique and adopt innovation to provide solutions to different problems faced by projects related to time, cost, and quality factors. Using project performance, measures, and assess the project and organizational performance in the entire project life cycle [4].

Artificial Intelligence (AI) has been employed in the construction industry for the past decade [5]. Moreover, the utilization of breakthrough tools such subfield of Artificial Intelligence Technique was in the position of creating a predictive model and in lieu of the progression of different practices to $4^{\text {th }}$ Industrial Revolution and can evaluate data sets with sequential and complex relationship utilizing a hybrid artificial neural network [6].

The principal goal of this study is to formulate a critical key indicator framework employing a construction analytics and reporting dashboard with a hybrid neural-based model for predicting the construction project performance of high-rise building projects in Metro Manila, Philippines.

\section{Methodology}

\subsection{Meta - Cognitive Analysis from Reviewing Literature and Conducting Surveys and Interviews with Experts}

Substantial number of studies has been utilized to investigate the factors influencing the project performance in different countries [7]. Through the meta-cognitive analysis from reviewing the literature of previous studies, many factors affecting the project performance rating were listed down. Then, 5 local experts in construction supervision, construction management, and consulting field have been interviewed and surveyed to help in developing the final list of influencing factors that will part of the assessment questionnaire. There are 18 influencing factors that were considered predominant factors for the project performance in correlation to cost, time, and quality indicators which is presented in table 1. 
Table 1. Factors affecting Cost Performance (CP), Time Performance (TP) and Quality Performance (QP) Rating.

\begin{tabular}{ll}
\hline Factor & Notation \\
\hline The total floor area of the building & $\mathrm{CP} 1 / \mathrm{TP} 1 / \mathrm{QP} 1$ \\
Issues arise on the project site & $\mathrm{CP} 2 / \mathrm{TP} 2 / \mathrm{QP} 2$ \\
Completeness of the contractor's plant and equipment & $\mathrm{CP} 3 / \mathrm{TP} 3 / \mathrm{QP} 3$ \\
Financial capacities of the general contractor & $\mathrm{CP} 4 / \mathrm{TP} 4 / \mathrm{QP} 4$ \\
Technical capacities of contractor's personnel & $\mathrm{CP} 5 / \mathrm{TP} 5 / \mathrm{QP} 5$ \\
Accessibility of trained resources & $\mathrm{CP} 6 / \mathrm{TP} 6 / \mathrm{QP} 6$ \\
Favourable working condition & $\mathrm{CP} 7 / \mathrm{TP} 7 / \mathrm{QP} 7$ \\
Nature of building & $\mathrm{CP} 8 / \mathrm{TP} 8 / \mathrm{QP} 8$ \\
Contractor's performance of achieving project finish date milestone & $\mathrm{CP} 9 / \mathrm{TP} 9 / \mathrm{QP} 9$ \\
Contractor's performance of achieving quality work & $\mathrm{CP} 10 / \mathrm{TP} 10 / \mathrm{QP} 10$ \\
Competency level of contractor's staff & $\mathrm{CP} 11 / \mathrm{TP} 11 / \mathrm{QP} 11$ \\
Level of occupational specialty requisite of contractors & $\mathrm{CP} 12 / \mathrm{TP} 12 / \mathrm{QP} 12$ \\
Subcontractor's knowledge and means & $\mathrm{CP} 13 / \mathrm{TP} 13 / \mathrm{QP} 13$ \\
Contractor's cost expenditure performance & $\mathrm{CP} 14 / \mathrm{TP} 14 / \mathrm{QP} 14$ \\
Design capacities when the budget is set & $\mathrm{CP} 15 / \mathrm{TP} 15 / \mathrm{QP} 15$ \\
Level of design complexity & $\mathrm{CP} 16 / \mathrm{TP} 16 / \mathrm{QP} 16$ \\
Climatic conditions at the project site & $\mathrm{CP} 17 / \mathrm{TP} 17 / \mathrm{QP} 17$ \\
Level of construction complexity & $\mathrm{CP} 18 / \mathrm{TP} 18 / \mathrm{QP} 18$ \\
\hline
\end{tabular}

\subsection{Neural Network Modelling}

Levenberg - Marquardt (trainlm) for training algorithm and Hyperbolic Tangent Sigmoid (tansig) for the transfer function was used in the development of the predictive mathematical model [8]. Furthermore, Levenberg - Marquardt emerges as the most advanced approach for medium - sized feed - forward ANN, and it may be implemented successfully to several hundred weights [9].

For this study, 18 hidden neurons and 2 hidden layers were used. Pearson's Correlation Coefficient (R), Mean Squared Error (MSE), and Mean Absolute Percentage Error (MAPE) were used as performance indicators [10]. The created model's efficacy and good level performance for cost, time and quality performance rating must have extremely high R values and extremely low MSE and MAPE values [11].

\subsection{Sensitivity Analysis}

A sensitivity analysis was implemented in this study through connection weights Garson's algorithm that was demonstrated to view the ranking of influence of the lists of factors of each performance rating [12].

\section{Results and Discussion}

\subsection{Neural Network Model Simulation Results}

The cost, time, and quality performance rating models have internal characteristics presented in Table 2. The training algorithm employed in model development was the Levenberg-tansig function. The number of hidden neurons used for the performance model development is equal to the Marquardt algorithm while the transfer function used 
is the tansig with " $m$ " number of hidden neurons [13]. The design of the developed performance rating models is shown in Figure 1.

Table 2. Description of the details of the cost, time and quality performance rating models.

\begin{tabular}{ll}
\hline Internal Characteristics & Value \\
\hline Training Algorithm & trainlm \\
Transfer Function & tansig \\
Number of Hidden Neurons & 18 \\
Number of Hidden Layers & $2(1$ Hidden Layer and 1 Output Layer $)$ \\
Performance Indicators & R, MSE and MAPE \\
\hline
\end{tabular}

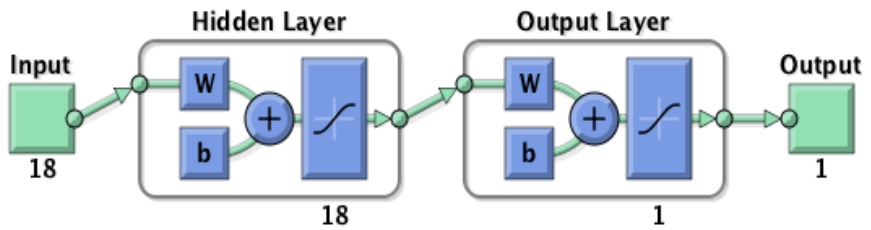

Figure 1. Design of the Performance Rating Models.

As demonstrated in Figure 2 to Figure 4, the performance rating models had a very high $\mathrm{R}_{\text {all }}$ value and a very low MSE and MAPE. The connection between the actual and anticipated performance ratings shows that the actual and predicted performance ratings are highly correlated.

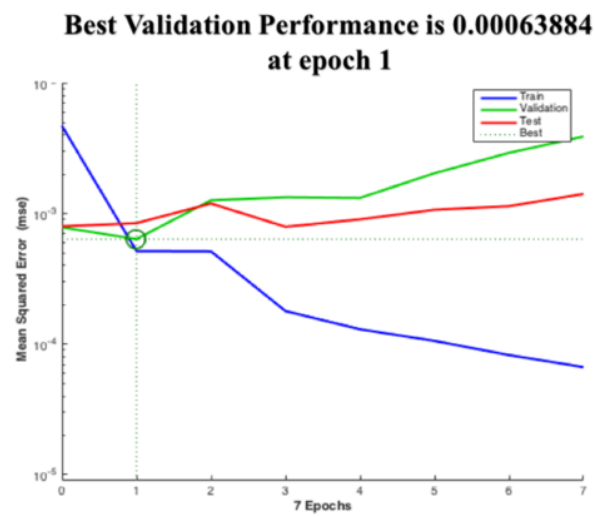

(a)
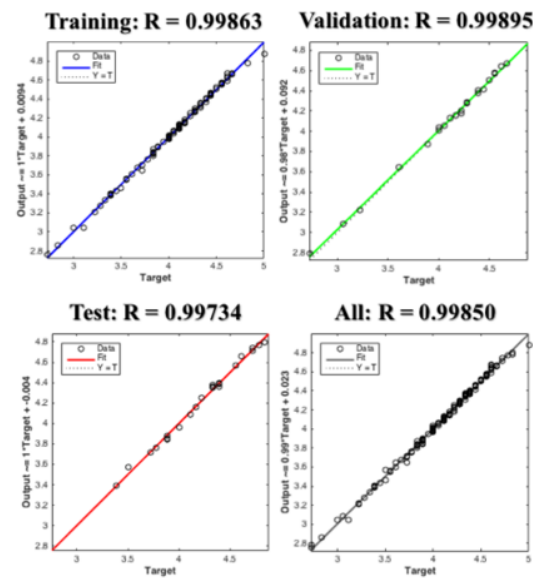

(b)

Figure 2. (a) Performance Plot and (b) Correlation Plots of the Cost Performance Rating Model. 


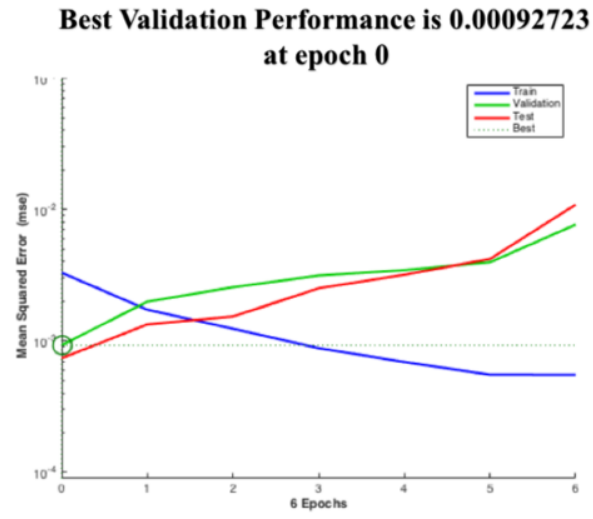

(a)

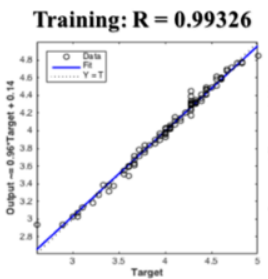

Validation: $\mathbf{R}=\mathbf{0 . 9 9 7 5 8}$
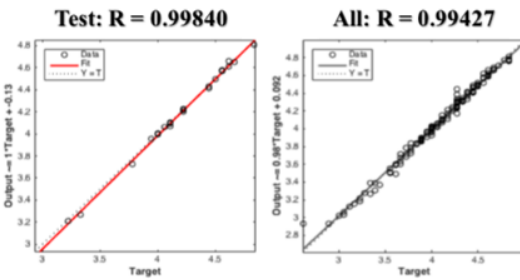

(b)

Figure 3. (a) Performance Plot and (b) Correlation Plots of the Time Performance Rating Model.

Best Validation Performance is $\mathbf{0 . 0 0 0 9 2 7 2 3}$ at epoch 0

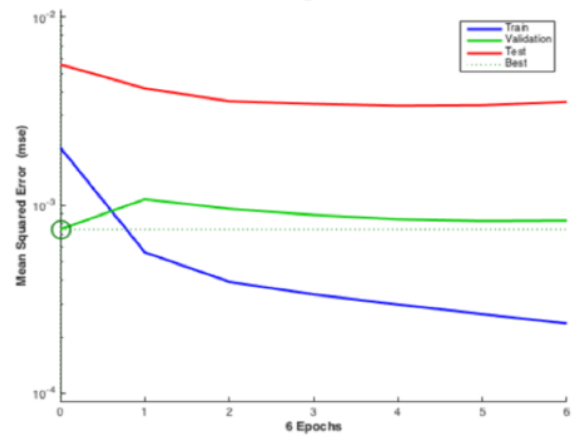

(a)
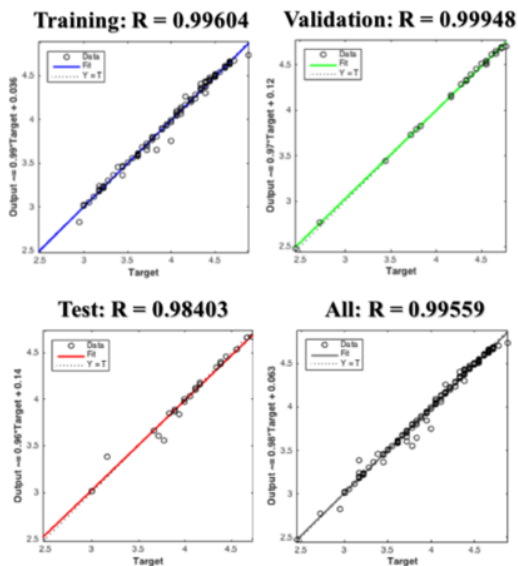

(b)

Figure 4. (a) Performance Plot and (b) Correlation Plots of the Quality Performance Rating Model.

\subsection{Variable Significance of the Parameters Influencing Cost, Time and Quality Performance Rating}

The variable significance of the factors affecting cost, time, and quality was calculated utilizing the connection weights of the network using Garson's Algorithm. Figure 5a presents the variable significance of the factors affecting cost performance rating. The ranking of influence of these factors is described as $\mathrm{CP} 18<\mathrm{CP} 4<\mathrm{CP} 17<\mathrm{CP} 13<\mathrm{CP} 11<\mathrm{CP} 15<\mathrm{CP} 12<\mathrm{CP} 8<\mathrm{CP} 2<\mathrm{CP} 9<\mathrm{CP} 6<\mathrm{CP} 3<\mathrm{CP} 1<\mathrm{CP} 10$ $<\mathrm{CP} 16<\mathrm{CP} 14<\mathrm{CP} 7<\mathrm{CP} 5$ wherein $\mathrm{CP} 18-$ a level of construction complexity is the least influential factor with R.I. $=4.13200 \%$ and CP5 - technical capacities of contractor's personnel are the most influential factor with $\mathrm{RI}=6.89412 \%$. 


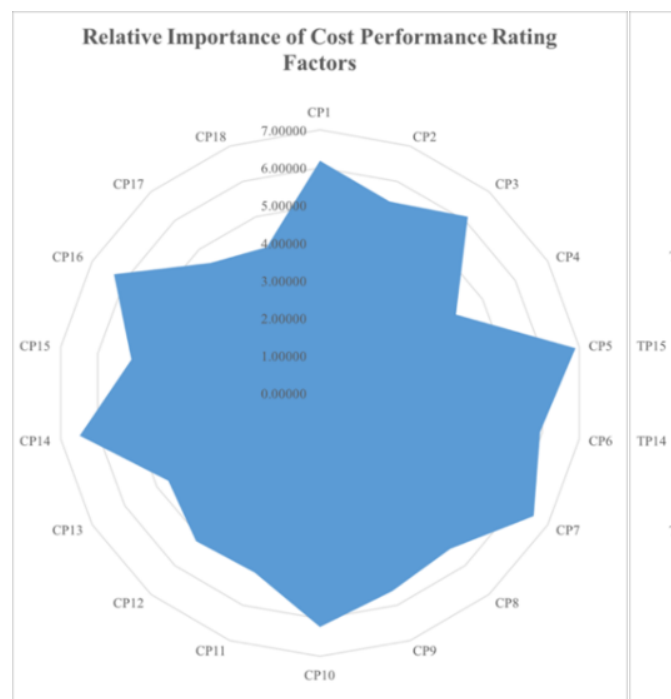

(a)

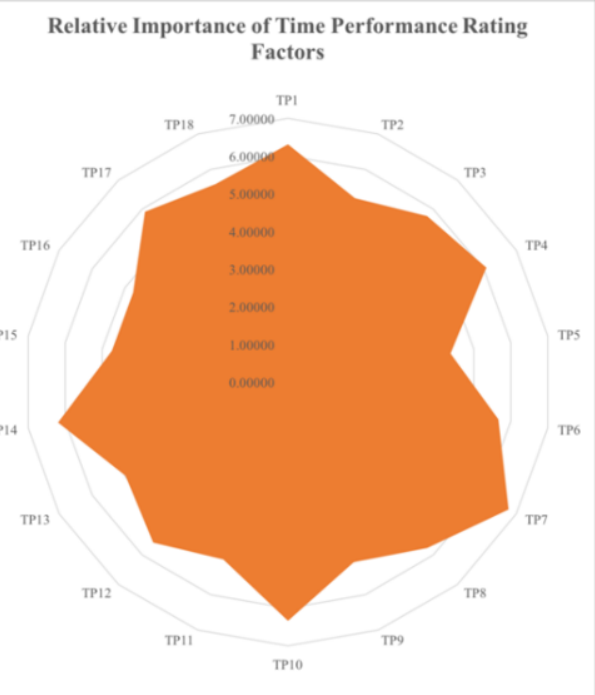

(b)

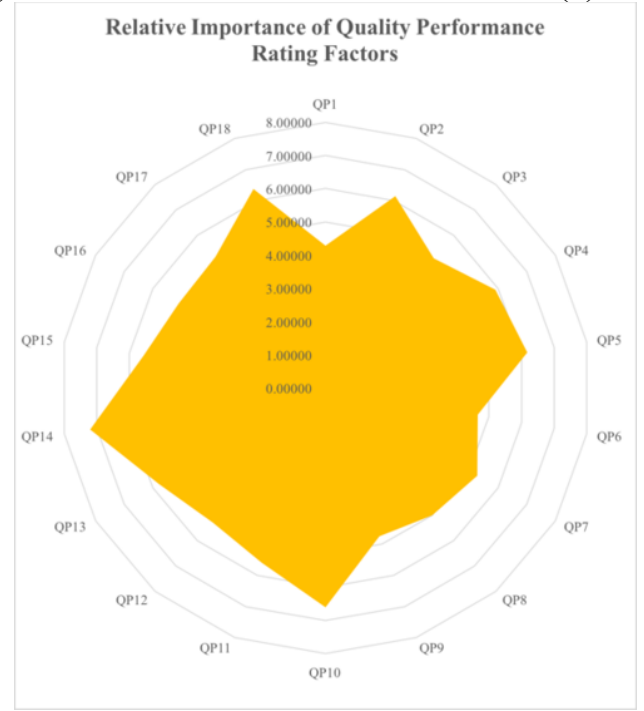

(c)

Figure 5. (a) Performance Plot and (b) Correlation Plots of the Quality Performance Rating Model.

Figure $5 \mathrm{~b}$ presents variable significance of the factors affecting time performance rating. The ranking of influence of these factors is described as $\mathrm{TP} 5<\mathrm{TP} 15<\mathrm{TP} 16<\mathrm{TP} 13<\mathrm{TP} 11<\mathrm{TP} 9<\mathrm{TP} 2<\mathrm{TP} 12<\mathrm{TP} 18<$

TP6 $<$ TP8 $<$ TP3 $<$ TP17 $<$ TP4 $<$ TP14 $<$ TP1 $<$ TP10 $<$ TP7 wherein TP5 - technical capacities of contractor's personnel is the least influential factor with R.I. $=4.37899 \%$ and TP7 favorable working conditions is the most influential factor with RI $=6.76326 \%$.

Figure 5c present the product weights and variable significance of the factors affecting quality performance rating. The ranking of influence of these factors is described 
$\mathrm{QP} 1<\mathrm{QP} 6<\mathrm{QP} 9<\mathrm{QP} 8<\mathrm{QP} 3<\mathrm{QP} 16<\mathrm{QP} 17<\mathrm{QP} 7<\mathrm{QP} 12<\mathrm{QP} 15<\mathrm{QP} 11<\mathrm{QP} 13<\mathrm{QP} 4<\mathrm{QP}$ $2<\mathrm{QP} 5<\mathrm{QP} 18<\mathrm{QP} 10<\mathrm{QP} 14$ wherein QP1 - total floor area of the building is the least influential factor with R.I. $=4.27745 \%$ and QP14 - contractor's cost expenditure performance is the most influential factor with $\mathrm{RI}=7.20907 \%$.

\subsection{KPI Dashboard}

As the actual data gathered and validated by the staff of the project with the approval of the site management, this engineering tool able to provide a solution to unseen and overlook problems and issues faced by the project. With this tool, easy access to the status of the late response of the designer and the project management on the review of submittals and the pending raise claims as events that will part in the substantiation for the claim. Furthermore, the productivity output of the manpower can be seen and evaluated instantly and assess its result from the standard requirement of the project. Lastly, with the help of this KPI Dashboard shown in Figure 6, the site management, and the high management of a local company able to picture-out the real-time condition of the project.

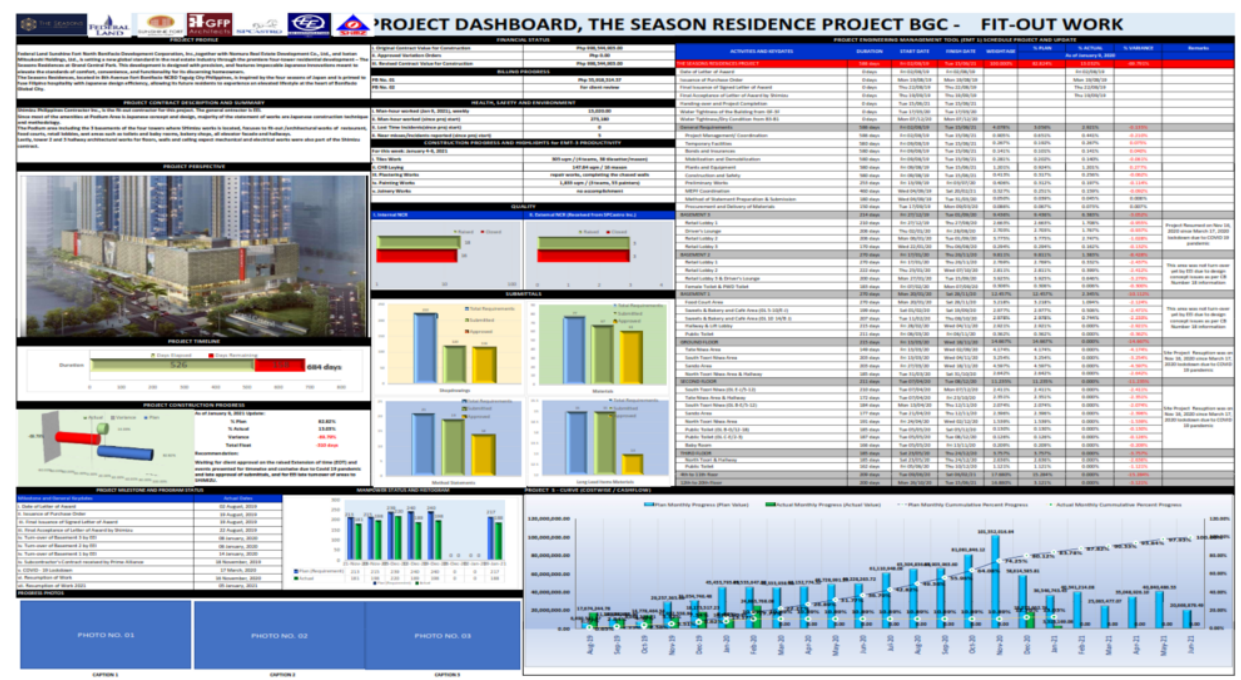

Figure 6. Developed KPI Dashboard. 


\section{Conclusion}

The created performance rating models for cost, time and quality has exceptionally high $\mathrm{R}$ values and extremely low MSE and MAPE values, indicating the proposed model's efficacy and performance.

Garson's algorithm was used to calculate the variable significance of the factors for performance rating of time, cost, and quality. The result is close to the output of actual validation and evaluation conducted on one of an on-going high-rise building project in Manila, Philippines. This is as per their actual progress on the different performance indicators using construction reporting dashboards.

To sum up, project performance can be measured, and the output presented on the training and validation test of one high-rise building projects show that the developed model can be a guide for on-going and future projects. Thus, the artificial neural network is suitable and effective for predicting construction project performance.

\section{References}

[1] Cabuñas J, Silva D. Exploratory factor - Item analytic approach for construction project cost overrun using oblique promax rotation for predictors determination. Int J Innov Technol Explor Eng. 2019; 8: $2278-$ 3075.

[2] Alias M, Dhanya R, Ramasamy G. Study on factors affecting the performance of construction projects and developing a cost prediction model using ANN. Int J. Earth Sci. Eng. 2015; 8(5): 2189 - 2194.

[3] Mossalam A, Arafa M. Using artificial neural networks (ANN) in projects monitoring dashboard's formulation, housing, and building national research center. HBRC J. 2018; 14(3): 385 - 392.

[4] Omar MN, Fayek AR. Modeling and evaluating construction project competencies and their relationship to project performance Autom Constr. 2016; 69: 115 - 130.

[5] Golnaraghi S, Zangenehmadar Z, Moselhi O, Alkass S. Application of artificial neural network (s) in predicting formwork labour productivity. Adv Civ Eng 2019. 2019.

[6] Yu THK, Huarng KH. A neural network-based fuzzy time-series model to improve forecasting. Expert Syst Appl. 2010; 37(4): 3366 - 3372.

[7] Jha K. Construction project management: Theory and practice. India: Pearson Education; 2011.

[8] Laroza Silva D, Marcelo De Jesus KL. Backpropagation Neural Network with Feature Sensitivity Analysis: Pothole Prediction Model for Flexible Pavements using Traffic and Climate Associated Factors. In 2020 the 3rd International Conference on Computing and Big Data; 2020; New York, NY, USA: Association for Computing Machinery, $60-67$.

[9] Hagan MT, Menhaj MB. Training feedforward networks with the Marquardt Algorithm. IEEE trans neural netw. 1994; 5(6): 989 - 993.

[10] Anupama S. Prediction of construction project performance using regression analysis and artificial neural network. Int J Res Appl Sci Technol. 2018; 6(5): 1172 - 1179.

[11] Silva DL, de Jesus KLM, Villaverde BS, Adina EM. Hybrid Artificial Neural Network and Genetic Algorithm Model for Multi-Objective Strength Optimization of Concrete with Surkhi and Buntal Fiber. In Proceedings of the 2020 12th International Conference on Computer and Automation Engineering; $2020 ; 47-51$.

[12] Olden JD, Joy MK, Death RG. An accurate comparison of methods for quantifying variable importance in artificial neural networks simulation data. Ecol model. 2004; 178(3-4): 389 - 93.

[13] Kim D, Kim H, Chung D. A modified genetic algorithm for fast training neural networks. In International Symposium on Neural Networks; 2005 May; Berlin, Heidelberg: Springer; 660 - 665 . 